\title{
The Effects of Hevea bransiliensis Natural Rubber on Phospholipids Concentration of Experimental Rats
}

\author{
${ }^{1}$ Bawa Abubakar, ${ }^{2}$ Njoku O. U., ${ }^{3}$ Salihu Suleiman, ${ }^{2}$ Joshua Parker E., \\ ${ }^{2}$ Agu Chidozie V. And ${ }^{2}$ Okonkwo C. C. \\ ${ }^{I}$ Department Of Preliminary And Remedial Studies, Federal Polytechnic Mubi, Adamawa State, Nigeria. \\ ${ }^{2}$ Department Of Biochemistry, University Of Nigeria, Nsukka, Enugu State Nigeria. \\ ${ }^{3}$ Department Of Chemistry, Federal University Dutse, Jigawa State, Nigeria.
}

\begin{abstract}
The effects of Hevea bransiliensis natural rubber on phospholipid concentrations of experimental rats were analyzed. Forty albino wister rats of either sex weighing 140-450g were used. The rats were divided into five equal groups marked $A, B, C, D$ and $E$ of eight rats each, and each group was fed on different dietary regime $A, B, C, D$ and $E$ respectively as indicated in tables 1 and 2. Diet $A$, (the control) had no rubber seed oil in the diet, whereas diets $B, C, D$ and $E$ (the experimental) had 2\% refined rubber seed oil, $2 \%$ crude rubber seed oil, $4 \%$ refined rubber seed oil and $4 \%$ crude rubber seed oil by weight incorporated respectively. The results showed an increase in plasma phosphatide level for groups $B$ and A rats. Little increase in plasma phosphatide levels were found in groups $D, C$ and $E$ rats. The results of liver phospholipids showed an increase in phospholipids concentration of groups $C, D$ and $E$ rats compared to groups $B$ and $A$ (control) for the corresponding weeks.
\end{abstract}

Keywords: Hevea bransiliensis, Natural rubber, Phospholipids concentration and Diets.

\section{Introduction}

Phosphoric acid is esterified on one side with derivatives of either choline, ethanolamine, serine, inositol and another glycerol. The three components, choline, ethanolamine and serine contain basic nitrogen which bears a positive charge at physiological $\mathrm{pH}$. The remaining carbons of the glycerol moiety are esterified with either saturated or unsaturated fatty acids. The phospholipids can be divided into two general groups: Glycerophosphatides and sphingosyl phosphatide [1].

It has long been known that phospholipids are responsible for the differential permeability of cells [2] and they are important regulators of cellular ionic exchange activities as indicated by [3]. According to [3] the existence of phosphatidyl serine in membranes is related to ion $\left(\mathrm{Na}^{+}, \mathrm{K}^{+}\right)$transport.

Lately, it has been realized that phosphatides play an important role in the pathological changes in malaria [4]. They can act as antigens [4]. The presence of phospholipids in a protective antigen indicates their possible involvement in the production of immunity against malaria.

Natural rubbers, (Hevea brasiliensis and Fantumia elastica) are two species of rubber trees found in the humid belt of the tropics. The latter species appears to have a more restricted geographic distribution to the lowland rainforest belt of West Africa, whereas Hevea brasiliensis extends in the humid tropical belt from Brazil in the West, through West and Central Africa to India, Malaysia and Indonesia in the East [5].

\section{Meterial And Methods}

Materials

Forty albino wister rats of either sex weighing $140-450 \mathrm{~g}$ were used for this analysis. The rats were obtained from the animal house of National Institute of Trypanosomonas Research Centre, Vom in Plateau State, Nigeria. They were kept in stainless steel cages with raised wire floors in a room maintained at $37^{\circ} \mathrm{C}$. The animals were fed for a period of 12 weeks. The rats were divided into five equal groups marked A, B, C, D and $\mathrm{E}$ of eight rats each, and each group was fed on different dietary regime A, B, C, D and E respectively as indicated in tables 1 and 2. Diet A, (the control) has no rubber seed oil in the diet, whereas diets B, C, D and E (the experimental) had 2\% refined rubber seed oil, $2 \%$ crude rubber seed oil, $4 \%$ refined rubber seed oil and $4 \%$ crude rubber seed oil by weight incorporated respectively.

The rats were initially starved for $24 \mathrm{~h}$ before being fed adlibitum with the various diets. Measurement of the liver cholesterol levels were carried out at the beginning of the experiment and subsequently at the end of every four weeks throughout the period of experiment, except the histochemical investigation of the liver that was done initially at the end of three months. 
Table 1: Feeding patterns with rubber seed oil incorporated diet

(Njoku, O.U. and Ononogbu, I.C., 1996).

\begin{tabular}{|c|c|c|c|c|c|}
\hline $\begin{array}{l}\text { Group/Treatment of } \\
\text { Rations \% }\end{array}$ & $\mathrm{A}$ & B & $\mathrm{C}$ & $\mathrm{D}$ & $E$ \\
\hline Fish meal & 10 & 10 & 10 & 10 & 10 \\
\hline Ruber seed oil & - & 2 & 2 & 4 & 4 \\
\hline
\end{tabular}

Table 2: Components of rat feed/100g edible portion modified by (Njoku, O.U. and Ononogbu, I.C., 1996).

\begin{tabular}{|l|l|l|l|l|l|l|l|}
\hline & Water $(\mathrm{ml})$ & Protein $(\mathrm{gm})$ & Fat $(\mathrm{gm})$ & $\begin{array}{l}\text { Carbohydrate } \\
(\mathrm{gm})\end{array}$ & Fibre (gm) & Mineral (gm) & Vitamin (gm) \\
\hline Maize flour & 12 & 10 & 4.5 & 71 & 2.0 & 14.5 & 2.48 \\
\hline $\begin{array}{l}\text { Groundnut } \\
\text { cake }\end{array}$ & 6 & 27 & 45 & 17 & 3.0 & 52.5 & 18.05 \\
\hline Fish meal & 20 & 63 & 6.3 & - & - & 3008 & 6.3 \\
\hline $\begin{array}{l}\text { Rubber seed } \\
\text { oil }\end{array}$ & 3.98 & 22.30 & 42.6 & - & 4.20 & 2.9 & - \\
\hline
\end{tabular}

\section{Extraction Of Rat Blood Plasma}

Five rats from each group were anaesthetized with chloroform and blood was withdrawn by cardiac puncture. Just before anesthesia, light was shone on the rats to increase the rate of blood flow into the syringe tubes. $3 \mathrm{ml}$ of blood drawn into EDTA (3 drops per $1.0 \mathrm{ml}$ of blood was centrifuged for 10 minutes at $10,000 \mathrm{~g}$ and the plasma (straw coloured liquid) which rises to the top was removed by Pasteur pipette as not to disturb the buffy layer of blood cells. The plasma was stored at $4^{\circ} \mathrm{C}$ until analysis and was analyzed within two days of extraction.

\section{COLORIMETRIC DETERMINATION OF PHOSPHOLIPIDS WITH AMMONIUM FERROTHIOCYANATE}

Plasma samples were extracted with chloroform and methanol. On separating $1.0 \mathrm{ml}$ of each chloroform extracts was removed with syringe and concentrated to dryness in a stream of air at $50^{\circ} \mathrm{C}$. The dried extract of phospholipids was then dissolved in $2.0 \mathrm{ml}$ of chloroform, added to $2.0 \mathrm{ml}$ of ammonium ferrothiocyanate in a total mixer. Following phase separation, the lower chloroform phase was removed with a Pasteur pipette and the chloroform phase was removed with a Pasteur pipette and the optical density measured at $448 \mathrm{~nm}$ in a $10 \mathrm{x}$ $75 \mathrm{~mm}$ curvette and standard curve was plotted.

\section{LIVER, KIDNEY AND PLASMA PHOSPHOLIPIDS DETERMINATION}

The liver, kidney and Adipose tissue was homogenized using phosphate buffer ( $\mathrm{pH}$ 6.2) and the lipid was recollected using chloroform - acetone mixture. The homogenate was centrifuged and the supernatant was collected and analyzed for phospholipid using Stewart 1980 colorimetric method as in the case of plasma phospholipid.

\section{Results}

Table 3: Mean plasma phospholipids concentration $(\mathrm{mg} / 100 \mathrm{ml})$

\begin{tabular}{|c|c|c|c|c|c|}
\hline & Groups & & & & \\
\hline Weeks & $\mathbf{A}$ & B & C & D & $\mathbf{E}$ \\
\hline 0 & $74.5 \pm 2.00$ & $45.0 \pm 3.00$ & $39.0 \pm 2.50$ & $35.0 \pm 3.50$ & $42.5 \pm 0.50$ \\
\hline 4 & $79.5 \pm 2.50$ & $84.0 \pm 0.50$ & $49.5 \pm 2.50$ & $62.0 \pm 2.00$ & $47.5 \pm 4.50$ \\
\hline 8 & $95.0 \pm 3.00$ & $98 / .0 \pm 0.50$ & $64.0 \pm 4.00$ & $73.0 \pm 5.00$ & $60.0 \pm 0.50$ \\
\hline 12 & $80.0 \pm 2.00$ & $46.0 \pm 2.00$ & $38.0 \pm 1.50$ & $34.0 \pm 1.50$ & $44.0 \pm 2.50$ \\
\hline
\end{tabular}

Table 4: Mean liver phospholipids concentration $(\mathrm{mg} / 100 \mathrm{ml})$

\begin{tabular}{|l|l|l|l|l|l|}
\hline & Groups & B & C & D & E \\
\hline Weeks & A & $66.5 \pm 2.50$ & $80.0 \pm 2.00$ & $81.0 \pm 2.00$ & $85.0 \pm 2.50$ \\
\hline 0 & $60.5 \pm 2.00$ & $82.0 \pm 0.50$ & $89.0 \pm 5.00$ & $92.0 \pm 2.00$ & $96.0 \pm 2.00$ \\
\hline 4 & $70.5 \pm 1.50$ & $90.5 \pm 1.50$ & $109.0 \pm 2.00$ & $103.0 \pm 0.50$ & $109.0 \pm 2.00$ \\
\hline 8 & $76.5 \pm 1.50$ & $70.0 \pm 3.00$ & $88.0 \pm 2.00$ & $82.0 \pm 0.50$ & $92.0 \pm 2.00$ \\
\hline 12 & $62.0 \pm 2.00$ & &
\end{tabular}


Table 5: Mean kidney phospholipids concentration (mg/100ml)

\begin{tabular}{|c|c|c|c|c|c|}
\hline & Groups & & & & \\
\hline Weeks & $\mathbf{A}$ & B & $\mathbf{C}$ & D & $\mathbf{E}$ \\
\hline 0 & $48.5 \pm 1.50$ & $25.0 \pm 2.00$ & $20.0 \pm 2.00$ & $35.0 \pm 3.00$ & $42.5 \pm 2.50$ \\
\hline 4 & $62.0 \pm 2.00$ & $24.0 \pm 2.00$ & $18.0 \pm 0.50$ & $47.5 \pm 4.50$ & $54.0 \pm 2.00$ \\
\hline 8 & $73.5 \pm 1.50$ & $31.0 \pm 0.50$ & $28.0 \pm 0.50$ & $53.0 \pm 1.00$ & $60.0 \pm 0.50$ \\
\hline 12 & $50.0 \pm 2.00$ & $22.0 \pm 0.50$ & $20.0 \pm 2.00$ & $38.0 \pm 2.00$ & $46.0 \pm 2.00$ \\
\hline
\end{tabular}

\section{Discussion}

Table 3 shows the mean plasma phospholipids concentration for the various groups A, B, C, D and E for the corresponding weeks. Generally, there seems to be a corresponding increase in plasma phosphatide level for groups B, and A and little increase for groups D, C and E. Whereas group B (2\% refined rubber seed oil incorporated diet) and A (control) rats had a substantial increase in plasma phosphatide level, groups D, C and E animals had a lower phosphatide level for the corresponding weeks. Also, mean liver phospholipids concentration were analyzed as shown in (Table 4). The results generally showed increase in liver phospholipids concentration but higher phospholipids concentration were seen in groups $\mathrm{C}, \mathrm{D}$ and $\mathrm{E}$ compared to groups $\mathrm{B}$ and A (control) for the corresponding weeks. The mean kidney phospholipids concentration was analyzed as shown in (table 5). The results generally showed higher level of phosphatide in groups A (control) and E (4\% crude rubber seed oil incorporated diets) while with or no mean increase of phosphatide level in group B, and C animals while in group D the increase in phosphatide level was close to that of group $\mathrm{E}$ and $\mathrm{A}$.

\section{Conclusion}

In conclusion, the results indicated that diets incorporated with rubber seed oil generally increased in plasma, kidney and liver phospholipids.

\section{References}

[1]. Abumrad, N.A., Stearns, S.B., Tepperman, H.M. and Tepperman, J.J. Lipid Res. 19, 423-432 (1978). In: The Lipid Composition of Adipose Tissue in Pro. Lipid Res. Vol. 27. Pp. 39-60.

[2]. Bashes, S., Blecker, C., Deroanne, C., Driva, N. E., and Hamadi, A., (2004). Date Seeds: Chemical Composition and Characteristics Profiles of the Lipid Fraction. Food Chemistry 84. Pp. 577-584.

[3]. Carroll, K.K. (1978). Protein in Nutri-relation to plasma cholesterol levels and atherosclerosis. Nutri-rev., 36, 1.

[4]. Harper, H.A. (1977) ed. Review of Physiological Chemistry. 15th edn., Lange med. Pub., California., pp. 300.

[5]. Henry; P.J. (1966). In: Clinical Chemistry. Harper and Row pub., New York., 1966; pp. 843-864. 